\title{
Multiple Monohydroxylation Products from rac-Camphor by Marine Fungus Botryosphaeria sp. Isolated from Marine Alga Bostrychia radicans
}

\author{
Hugo C. R. de Jesus, ${ }^{a, b, c}$ Alex H. Jeller, ${ }^{d}$ Hosana M. Debonsi, ${ }^{e}$ Péricles B. Alves ${ }^{b}$ and \\ André L. M. Porto*,a \\ aLaboratório de Química Orgânica e Biocatálise, Instituto de Química de São Carlos, \\ Universidade de São Paulo, Av. João Dagnone, 1100, Ed. Química Ambiental, J. Santa Angelina, \\ 13563-120 São Carlos-SP, Brazil \\ ${ }^{b}$ Departamento de Química, Universidade Federal de Sergipe, São Cristóvão, \\ 49100-000 Aracajú-SE, Brazil \\ 'Laboratório Dalton de Espectrometria de Massas, Instituto de Química, Universidade Estadual de \\ Campinas (UNICAMP), 13803-862 Campinas-SP, Brazil \\ ${ }^{d}$ Centro de Estudos em Recursos Naturais, Universidade Estadual de Mato Grosso do Sul, \\ Rod. Itahum Km 12, s/n, 79804-970 Dourados-MS, Brazil \\ eDepartamento de Física e Química, Faculdade de Ciências Farmacêuticas de Ribeirão Preto, \\ Universidade de São Paulo, Via do Café s/n, 14040-903 Ribeirão Preto-SP, Brazil
}

\begin{abstract}
This manuscript describes the biooxidation of rac-camphor using whole cells of marine-derived fungus Botryosphaeria sp. CBMAI 1197. The main biotransformation products of this monoterpene were achieved via a hydroxylation reaction and occurred with 5 days of rac-camphor incubation. Products were identified by means of gas chromatography mass spectrometry (GC-MS) and nuclear magnetic resonance (NMR) data. The major hydroxylated products were 6-endo-hydroxycamphor, 6-exo-hydroxycamphor, 5-exo-hydroxycamphor, 5-endo-hydroxycamphor, 3-exo-hydroxycamphor and 8-hydroxycamphor. The 6-exo-hydroxycamphor was obtained through a retro-aldol reaction when 6-endo-hydroxycamphor was maintained in presence of $\mathrm{CDCl}_{3}$; this isomerization was confirmed by ${ }^{1} \mathrm{H}$ NMR and GC-MS data.
\end{abstract}

Keywords: terpene, hydroxylation, biocatalysis, marine endophytic fungi

\section{Introduction}

The mono and sesquiterpenes belong to the largest class of secondary metabolites. They are known not only as raw materials for flavor and fragrance, but also as biologically active substances. ${ }^{1}$ The (-)-camphor is a bicyclic monoterpene and is one of the oldest known organic compounds. It is a major constituent of essence of dalmatian sage (Salvia officinalis). ${ }^{2,3}$ It has a camphoraceous odor and is used commercially as a moth repellent and in skin care formulations for cosmetic and pharmaceutical purposes. ${ }^{4}$

Monoterpenes in plants have mainly ecological roles. They repel herbivores, minimize fungus, and attract

*e-mail: almporto@iqsc.usp.br pollinators. ${ }^{1}$ This class of compounds has been widely used for bactericidal, virucidal, fungicidal, antiparasitical, insecticidal, medicinal and cosmetic applications especially in pharmaceutical, sanitary, cosmetic, agricultural and food industries. .,6 $^{5}$

Considering the wide variety of applications and activities of monoterpenes, there are attempts to modify its basic structure to improve its properties. This can be accomplished by chemical synthesis and biotransformation reactions. However, organic synthesis is not typically satisfactory for performing structural modifications of terpenoids because of its low reactivity. This produces substances in poor yields.

The oxidation of inactivated $\mathrm{C}-\mathrm{H}$ bonds under mild conditions has no equivalent in classical synthetic methodologies; P450 enzymes also have significant 
potential in biotransformation applications. For example, cytochrome P450 from Pseudomonas putida catalyzed the selective oxidation of camphor to 5-exo-hydroxycamphor. ${ }^{7}$

There are few articles in the literature describing monohydroxylation of camphor. Nakahashi and Miyazawa ${ }^{8}$ used Salmonella typhimurium OY1000/2A6 of human cytochrome P450, employing the cofactor NADPH-P450 reductase. This hydroxylated the (-)-5-exo-hydroxycamphor and (-)-8-hydroxycamphor. Miyazawa and Miyamoto ${ }^{9}$ used the larvae of the common cutworm (Spodoptera litura) to biotransform rac-camphor to 5-endo-hydroxycamphor, 5-exo-hydroxycamphor (5) and 8-hydroxycamphor. However, to the best of our knowledge, there is not report on camphor biotransformation by marine fungi.

We recently investigated the bio-oxidation of natural products using marine-derived fungi. ${ }^{10}$ In this study, we used whole cells of Brazilian marine fungus Botryosphaeria sp. CBMAI 1197 in the biohydroxylation reaction of monoterpene rac-camphor (1). The fungus Botryosphaeria sp. CBMAI 1197 was isolated from red marine alga Bostrychia radicans. ${ }^{11}$ Therefore, different hydroxylated compounds were produced by fungal bioconversion of monoterpene.

\section{Experimental}

\section{General methods}

The rac-camphor (1) (> 96\%) used in the biotransformation experiments was purchased from SigmaAldrich. Technal T-421 and Superohm orbital shakers were employed in the biocatalytic transformation experiments. Sterile materials were used for the biotransformation experiments, and Botryosphaeria sp. CBMAI 1197 was handled in a Veco biological safety cabinet. Thin-layer chromatography (TLC) was performed on pre-coated plates (aluminum foil, silica gel $60 \mathrm{~F}_{254}$ Sorbent, $0.25 \mathrm{~mm}$, from Merck).

Enzymatic products were purified by column chromatography (CC) on silica gel $\left(\mathrm{SiO}_{2} ; 230-400\right.$ mesh, from Across) eluted with $n$-hexane/EtOAc mixtures in increasing polarity degrees. The products of $r a c$-camphor (1) analyses were carried out using Shimadzu 2010 GC/FID equipped with an auto-injector AOC20i and DB-5MS $(30 \mathrm{~m} \times 0.25,0.25 \mu \mathrm{m})$ column. The injector and detector temperature were maintained at $250{ }^{\circ} \mathrm{C}$, the split ratio of the injector was 1:20, the carrier gas was $\mathrm{He}$ at $88.2 \mathrm{kPa}$, and the flux was $1.5 \mathrm{~mL} \mathrm{~min}^{-1}$. The program used for gas chromatography (GC) analysis was as follows: initial temperature of $50{ }^{\circ} \mathrm{C}$, final temperature of $232{ }^{\circ} \mathrm{C}$, ramp rate of $7^{\circ} \mathrm{C}$, and final time of $30 \mathrm{~min}$.
The mass spectrometry (MS) used electron capture detection, electronic impact of $70 \mathrm{eV}$, scanning speed of 1,000 Da sec $\mathrm{De}^{-1}$, scan interval of 0.50 fragments $\mathrm{s}^{-1}$ and fragments detected from 40-500 Da. The ${ }^{1} \mathrm{H}$ and ${ }^{13} \mathrm{C}$ nuclear magnetic resonance (NMR) spectra were obtained on a Bruker/AC-200 spectrometer $\left({ }^{1} \mathrm{H}\right.$ at $200 \mathrm{MHz}$ and ${ }^{13} \mathrm{C}$ at $50 \mathrm{MHz}$ ). The spectra were obtained in deuterium chloroform $\left(\mathrm{CDCl}_{3}\right)$, and the chemical shifts are given in ppm with tetramethylsilane (TMS) as the internal standard.

Isolation, identification and preparation of stock cultures of marine-derived fungus Botryosphaeria sp. CBMAI 1197

The Botryosphaeria sp. CBMAI 1197 fungus strain was isolated from red marine alga Bostrychia radicans collected in Ubatuba in the South Atlantic Ocean off the northern coast of the state of São Paulo, Brazil, in September 2007 by Prof Hosana M. Debonsi (FCFRP/ USP). ${ }^{11}$ This alga was identified by conventional taxonomic methods by N. S. Yokoya (Botanical Institute of São Paulo, IBOT/SP, Brazil). A voucher specimen was deposited at the Herbarium of Botanical Institute of São Paulo, Brazil, under accession number SP 365678.

Stock cultures of the marine-derived fungus was stored in Petri dishes containing a $2 \%$ malt solid culture medium based on artificial sea water (ASW) $\left[\mathrm{CaCl}_{2} \cdot 2 \mathrm{H}_{2} \mathrm{O}\right.$ (1.36 g L $\left.{ }^{-1}\right), \mathrm{MgCl}_{2} \cdot 6 \mathrm{H}_{2} \mathrm{O}\left(9.68 \mathrm{~g} \mathrm{~L}^{-1}\right), \mathrm{KCl}\left(0.61 \mathrm{~g} \mathrm{~L}^{-1}\right)$, $\mathrm{NaCl}\left(30.0 \mathrm{~g} \mathrm{~L}^{-1}\right), \mathrm{Na}_{2} \mathrm{HPO}_{4}\left(0.014 \mathrm{mg} \mathrm{L}{ }^{-1}\right), \mathrm{Na}_{2} \mathrm{SO}_{4}$ (3.47 $\left.\mathrm{g} \mathrm{L}^{-1}\right), \mathrm{NaHCO}_{3}\left(0.17 \mathrm{~g} \mathrm{~L}^{-1}\right), \mathrm{KBr}\left(0.1 \mathrm{~g} \mathrm{~L}^{-1}\right)$, $\left.\mathrm{SrCl}_{2} \cdot 6 \mathrm{H}_{2} \mathrm{O}\left(0.040 \mathrm{~g} \mathrm{~L}^{-1}\right), \mathrm{H}_{3} \mathrm{BO}_{3}\left(0.030 \mathrm{~g} \mathrm{~L}^{-1}\right)\right]$, agar (20 $\left.\mathrm{g} \mathrm{L}^{-1}\right)$, and malt extract $\left(20 \mathrm{~g} \mathrm{~L}^{-1}\right)$. The $\mathrm{pH}$ of the medium was adjusted to 8 with $3 \mathrm{~mol} \mathrm{~L}^{-1} \mathrm{KOH}$. The Petri dishes were maintained at $4{ }^{\circ} \mathrm{C}$ for later use.

Biotransformation of rac-camphor (1) by marine-derived fungus Botryosphaeria sp. CBMAI 1197

The fungus was cultured in $250 \mathrm{~mL}$ Erlenmeyer flasks containing $100 \mathrm{~mL}$ of liquid culture medium with $2 \%$ malt extract ( 3 days, at $32{ }^{\circ} \mathrm{C}$ ) on an orbital shaker $(150 \mathrm{rpm})$ in ASW. After this time, the rac-camphor (1) $(50.0 \mathrm{mg})$ previously dissolved in $400 \mu \mathrm{L}$ of dimethyl sulfoxide was added and mixed into the liquid culture medium. The biocatalytic reactions were analyzed periodically (24, 48, 72, and $120 \mathrm{~h}$ ) by collecting $2 \mathrm{~mL}$ of samples and adding $2 \mathrm{~mL}$ of ethyl acetate with vortex mixing and then centrifuged at $6000 \mathrm{rpm}$ for $6.0 \mathrm{~min}$ in a HERMLEZ-200 A. The organic phase was analyzed by GC-FID and GC-MS. The experiments were conducted in triplicate. After $120 \mathrm{~h}$, the biotransformation products were isolated. 
Purification of hydroxylated products obtained by biotransformation of rac-camphor (1)

The isolation of the hydroxylated products was performed using CC; with stationary phase flash silica gel 60 (230-400 mesh) from Across. The separation progress was monitored by TLC on pre-coated silica gel 60 F254 from Sorbent Technologies. The samples were observed under UV light $(254 \mathrm{~nm})$ and developed with anisaldehyde solution $(100 \mathrm{~mL}$ of acetic acid, $1 \mathrm{~mL}$ of concentrated sulfuric acid and $1 \mathrm{~mL}$ of $p$-anisaldehyde) or alcoholic solution of vanillin $(125 \mathrm{~mL}$ ethanol, $25 \mathrm{~mL}$ of concentrated sulfuric acid and $6 \mathrm{~g}$ vanillin). Hexane and ethyl acetate was used as the mobile phase for elution of components. This started with $100 \%$ hexane $(175 \mathrm{~mL})$ and the polarity gradually increased: 9.5:0.5 $(75 \mathrm{~mL}), 9.0: 1.0(75 \mathrm{~mL})$, 8.5:1.5 (75 mL), 8.0:2.0 (150 mL), 7.5:2.5 (200 mL), 7.0:3.0 (200 mL), and 6.5:3.5 (100 mL).

\section{Results and Discussion}

Biotransformation of rac-camphor (1) by the whole cells of marine-derived fungus Botryosphaeria sp. CBMAI 1197

Botryosphaeria sp. CBMAI 1197 transformed the rac-camphor (1) to different hydroxylated products 2-7. The hydroxylation mediated by Botryosphaeria genus has been described in the literature in different natural products including biooxidation reactions of 3-keto-bisnorcholeno, nootkatone, ambrox, sclareol, sclareolide and valencene. ${ }^{12-14}$

We initially carried out a kinetic study of the biotransformation reaction of rac-camphor (1) up to $120 \mathrm{~h}$. After this period, the chromatographic profile obtained by GC-flame ionization detection (FID) analysis was unchanged indicating that the biotransformation was stabilized in these conditions. The biotransformation of rac-camphor (1) was mediated by whole cells from Botryosphaeria sp. CBMAI
1197 fungus. This demonstrated that products 2-7 formed at different reaction times $(24,72$ and $120 \mathrm{~h})$ and were maintained by the same chromatographic profile (had no change) during the biotransformation process (Figure 1). A control stability experiment was performed in which the liquid culture medium (absent of fungus) was added to the rac-camphor (1); the compound was stable for at least $120 \mathrm{~h}$ (Figure 1).

Several compounds may undergo spontaneous reactions. These are sometimes mistakenly associated with enzymatic conversions. Thus, rac-camphor (1) was added to the culture medium in the absence of fungus to study stability. The compound remained intact. Thus, the peaks in Figure 1 are products 2-7 due to biotransformation of rac-camphor (1) by enzymes from Botryosphaeria sp. CBMAI 1197.

In the biotransformation of rac-camphor (1) by Botryosphaeria sp. CBMAI 1197 were obtained six main metabolites 2-7, which were previously identified by mass spectrometry data. In addition, four substances $(\mathbf{3}, \mathbf{5 - 7})$ were isolated in mixture by chromatographic column and identified by NMR and MS analyses. All of the data were compared with those described in the literature (Scheme 1).

MS analysis of metabolites 2-7 showed a specific molecular ion peak $\left(\mathrm{M}^{+*}\right)$ at $\mathrm{m} / \mathrm{z} 168$, indicating the presence of a hydroxyl group added to the substrate $\left(152 \mathrm{~g} \mathrm{~mol}^{-1}\right)$ by Botryosphaeria sp. CBMAI 1197 (Figure 2).

Figure 3 shows the chromatogram (GC-MS) fractions (A-D) containing compounds 3-7 produced by biotransformation. The compounds were partially purified through normal phase chromatography column. These fractions showed the oxidized products 3-6. Compounds $\mathbf{3}$ and $\mathbf{5}$ were isolated with 81 and $75 \%$ purity, respectively, and were identified by NMR analyses (Figures 3A-B). Metabolites $\mathbf{6}$ and $\mathbf{7}$ were obtained as a mixture. These molecules were structurally identified by NMR data (Figures 3C-D). The fraction obtained by chromatographic separation and analyzed by GC-MS showed compound $\mathbf{3}$ in a mixture of substances 5-6 (Figure 3C). Therefore,

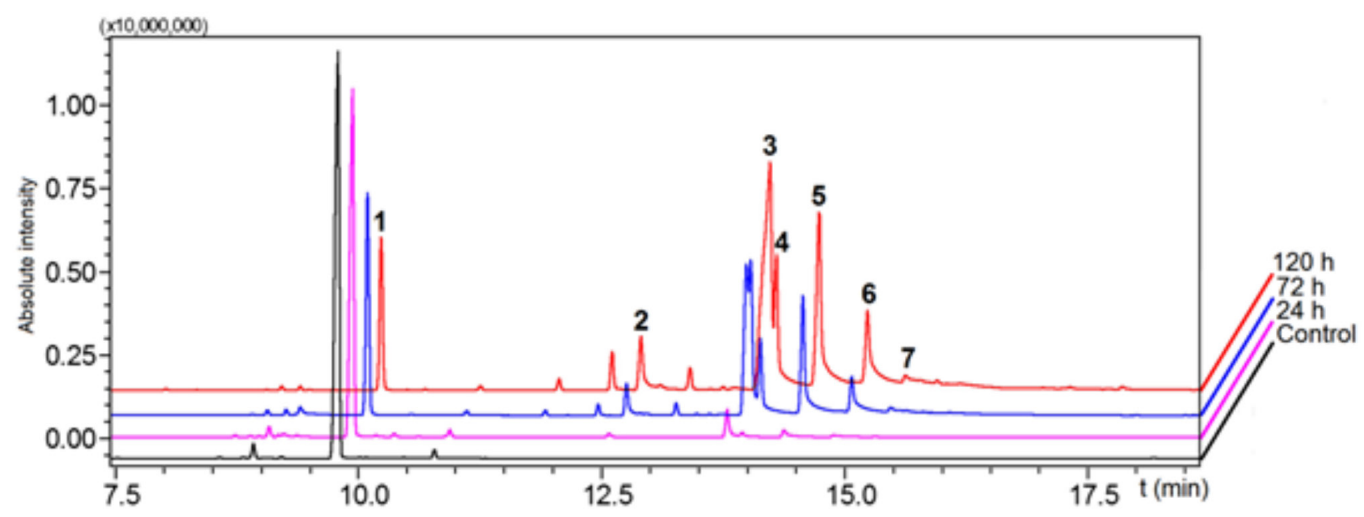

Figure 1. GC-FID analyses of biotransformation reaction of rac-camphor (1) by marine endophytic fungus Botryosphaeria sp. CBMAI 1197 in different times. Control: liquid culture medium plus rac-camphor (1) in fungus absence. 


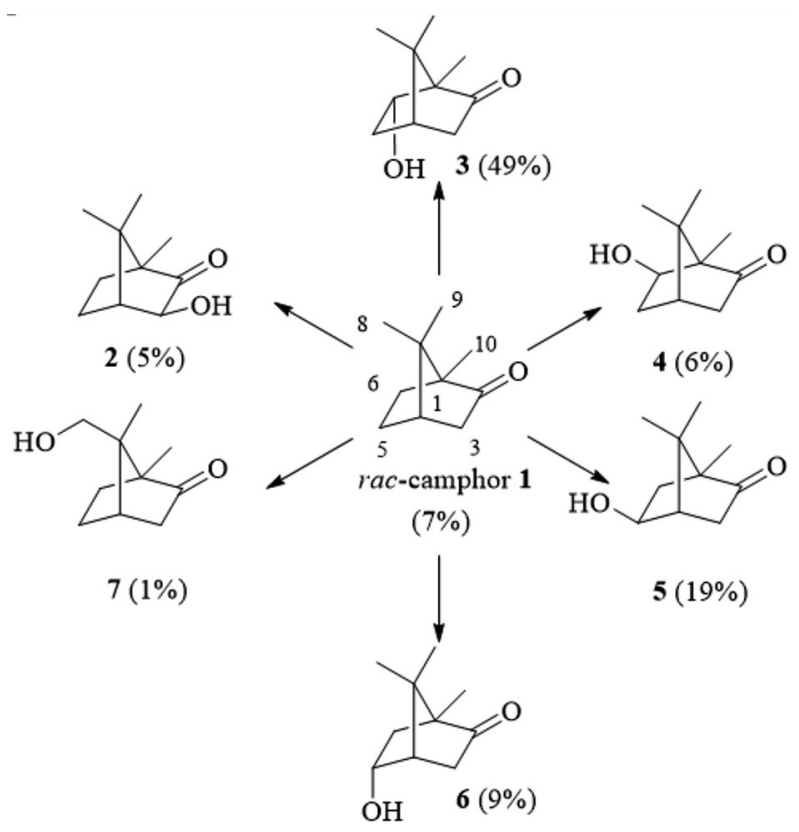

Scheme 1. Biohydroxylation of rac-camphor (1) by whole cells of Botryosphaeria sp. CBMAI 1197 yielding the compounds 2-7.
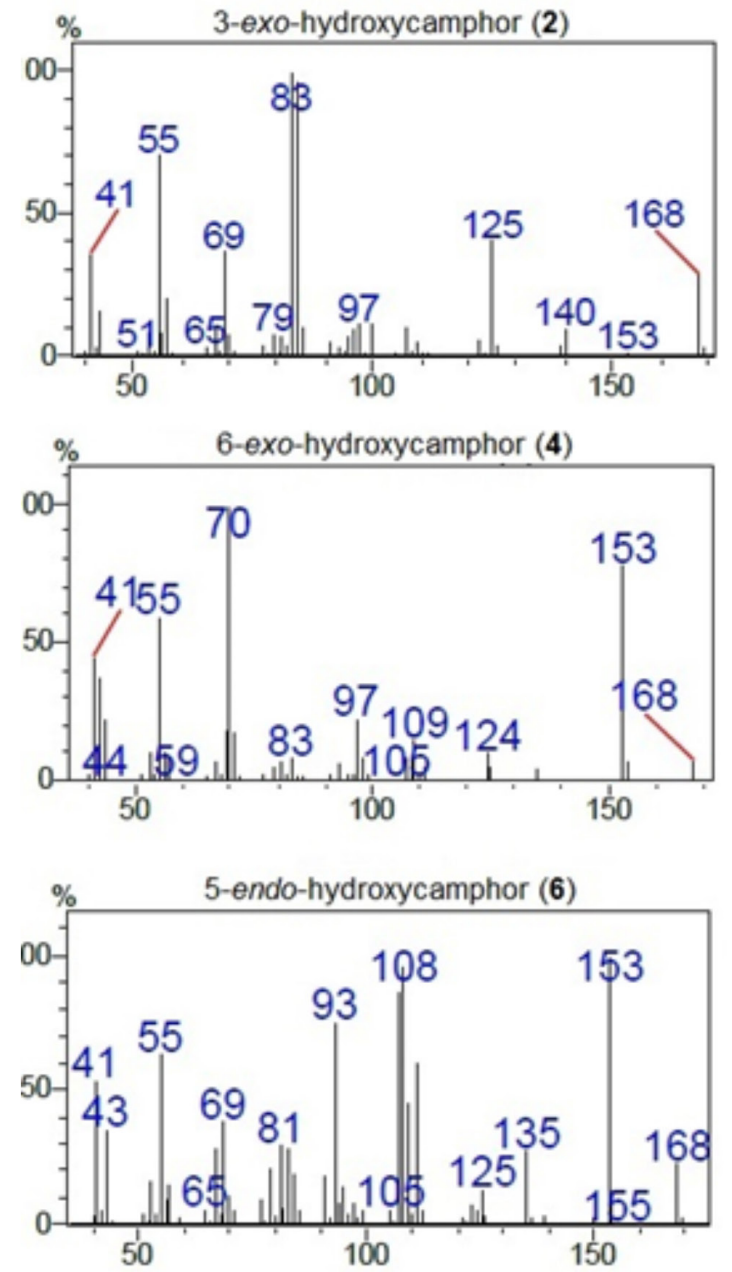

metabolite $\mathbf{6}$ was in mixture of compound $\mathbf{3}$ and $\mathbf{5}$. Compound $\mathbf{3}$ (majority in fraction C) was obtained in mixtures with metabolites 5-7. Compound 7 was identified in this mixture and could be seen in fraction D (Figure 3D). In addition, compound $\mathbf{2}$ was not isolated, and compound $\mathbf{4}$ was obtained from isomerization of compound $\mathbf{3}$.

The identification and characterization of hydroxylated compounds 2-7 are described here. The exact position of the hydroxyl group was confirmed by NMR and MS analyses of the substances (even in mixture). These were purified by flash chromatography column and compared with literature data. ${ }^{9}$ These substances obtained via biotransformation of rac-camphor (1) by Botryosphaeria sp. CBMAI 1197 were obtained as white solids.

The ${ }^{1} \mathrm{H}$ NMR spectra of the carbinolic hydrogen region showed that the fractions contained mixture of metabolites 3-7. This explained the position of the hydroxyl groups in rac-camphor (1) (Supplementary Information).

Fraction A (Figure 3A) had a peak at $\delta 9.86$. Surprisingly, this signal was not assigned to any hydrogen
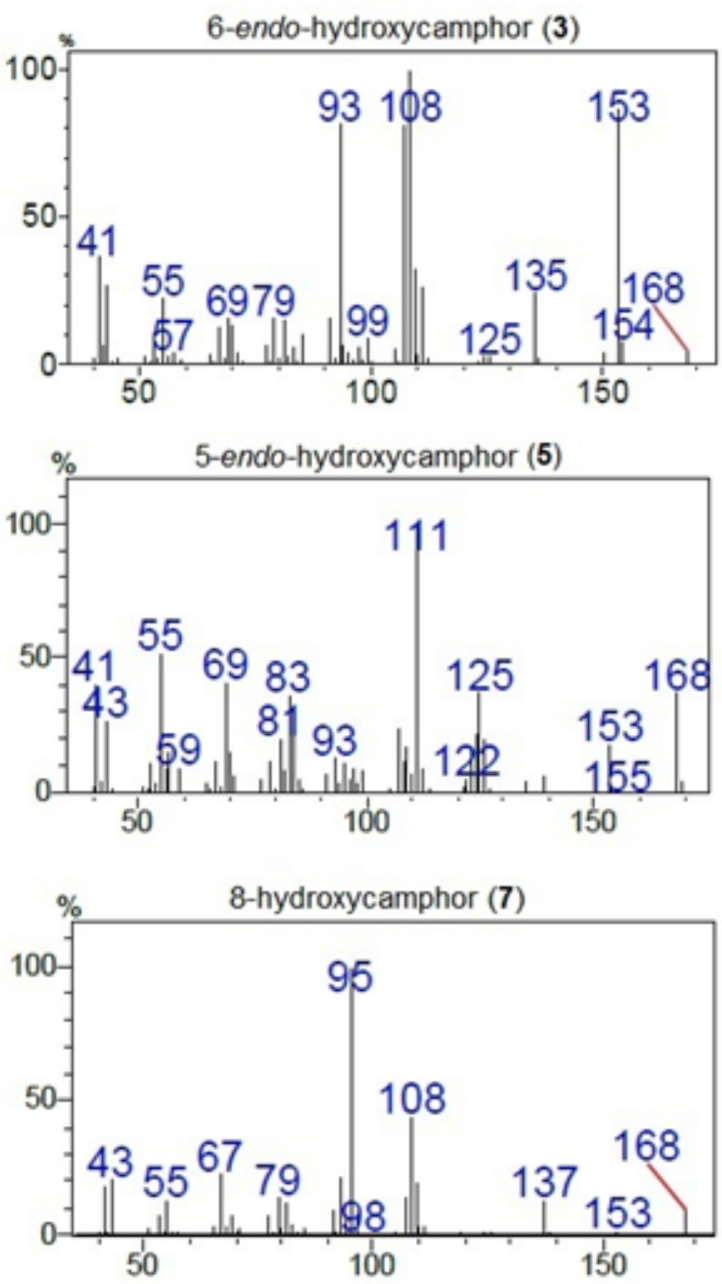

Figure 2. Mass spectra for the hydroxylated derivative metabolites 2-7 from rac-camphor (1) obtained by Botryosphaeria sp. CBMAI 1197. 

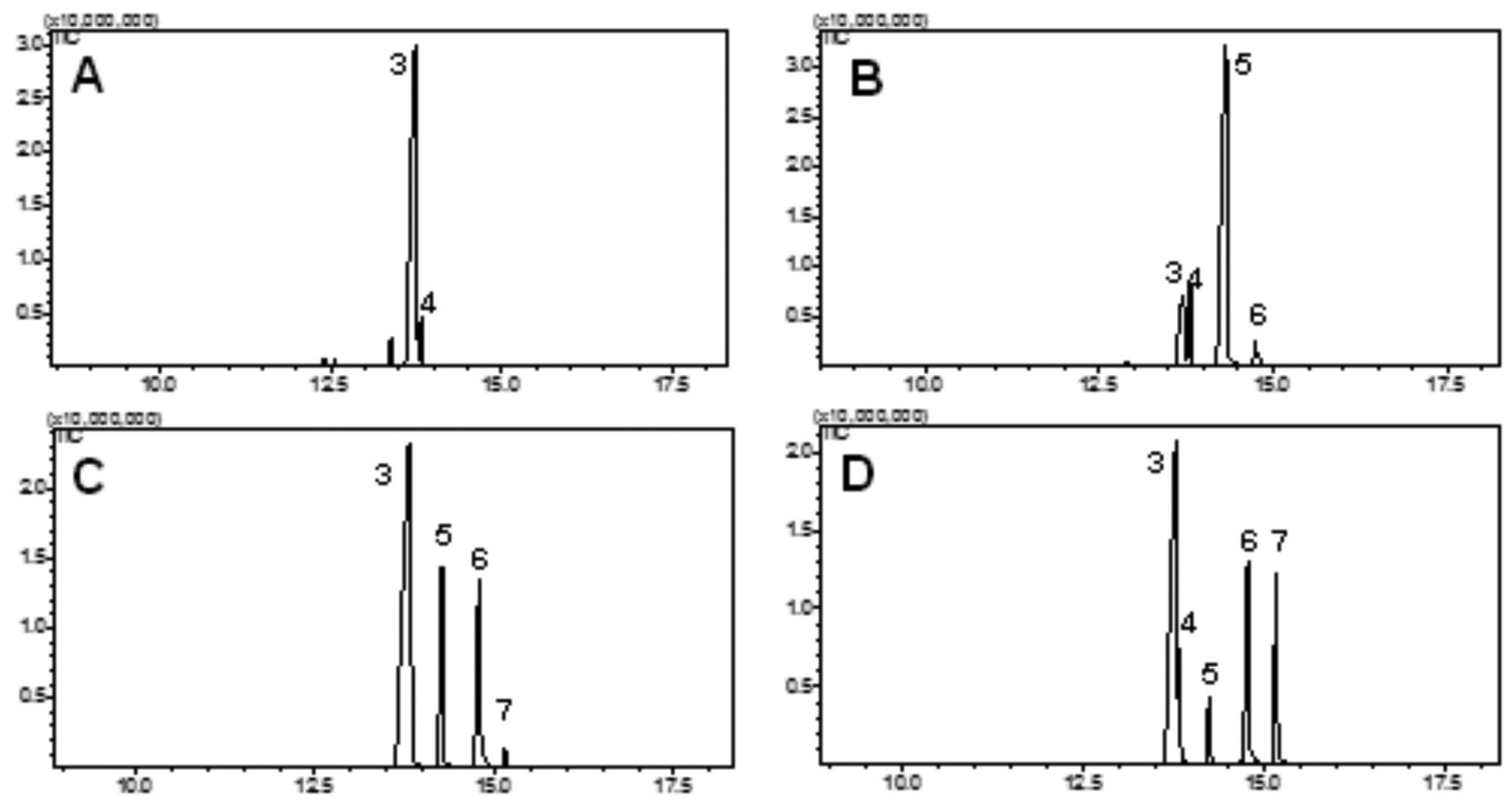

Figures 3. (A-D) GC-MS (70 eV) chromatograms of the fractions 3A-D containing the compounds 3-7 yield by biotransformation of rac-camphor (1) using Botryosphaeria sp. CBMAI 1197.

of the hydroxyl-camphor metabolite. The signal at $\delta 9.86$ was obtained from an aldehyde intermediate when the sample of 6-endo-hydroxycamphor (3) was solubilized in deuterated chloroform. According to Grogan et al. ${ }^{15}$ the 6-endo-hydroxycamphor (3) undergoes an isomerization through a retro-aldol reaction confirmed with ${ }^{1} \mathrm{H}$ NMR shield at $9.86 \mathrm{ppm}$. Scheme 2 shows the spontaneous isomerization mechanism of 6-endo-hydroxycamphor (3) to obtain the 6-exo-hydroxycamphor (4) (NMR spectrum, Supplementary Information).

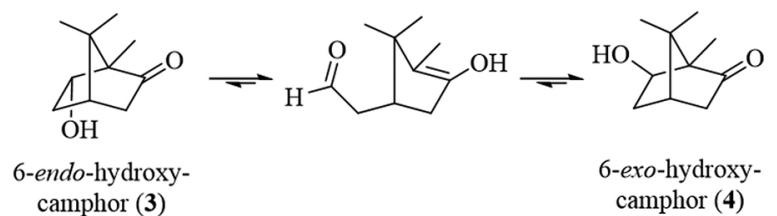

Scheme 2. Spontaneous isomerization of 6-endo-hydroxycamphor (3) to 6-exo-hydroxycamphor (4) in presence of $\mathrm{CDCl}_{3}$.

GC-MS analysis after dilution of the sample containing 6-endo-hydroxycamphor (3) in presence of $\mathrm{CDCl}_{3}$ after 16 hours confirmed the existence of isomerization (Figure 4 and Scheme 2). The 6-exo-hydroxycamphor (4) signal increased and the peak of 6-endo-hydroxycamphor (3) decreased (Figures $3 \mathrm{~A}$ and 4 ). The increased stability of the 6-exo-diastereomer (4) explains the balance shift.

In the ${ }^{1} \mathrm{H}$ NMR spectrum of fraction $\mathrm{A}$ (Figure $3 \mathrm{~A}$ and Supplementary Information), we noted a double doublet at $\delta_{\mathrm{H}} 4.18(J=8.0$ and $2.0 \mathrm{~Hz})$ that was attributed to 6-exo-

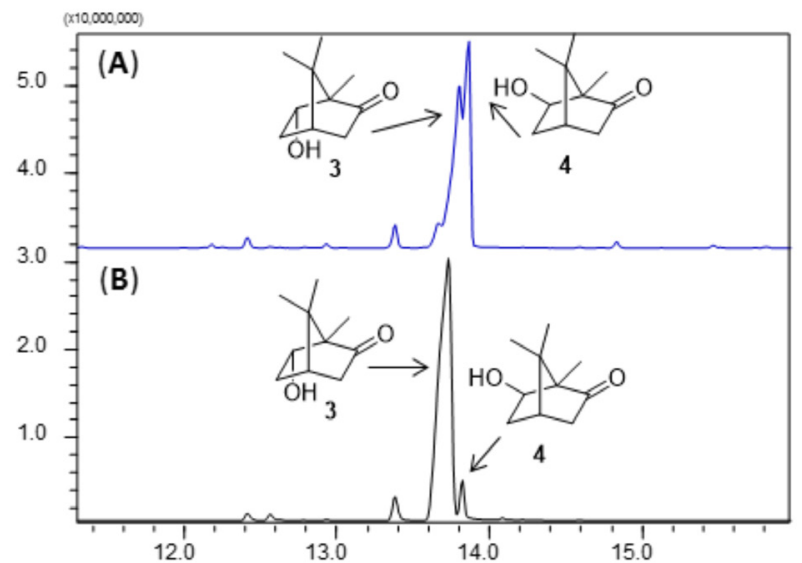

Figure 4. Chromatograms obtained by GC-MS analysis. (A) Spontaneous isomerization of 6-endo-hydroxycamphor (3) to 6-exo-hydroxycamphor (4) in presence of $\mathrm{CDCl}_{3}$; (B) 6-endo-hydroxycamphor (3) in absence of $\mathrm{CDCl}_{3}$.

hydrogen of 6-endo-hydroxycamphor (3). Therefore, the structural characterization of hydroxylated metabolite 3 was carried out by ${ }^{1} \mathrm{H}$ NMR analysis. This showed the presence of methyl groups at $0.83 \mathrm{ppm}(3 \mathrm{H}, \mathrm{s})$ and $0.98 \mathrm{ppm}(6 \mathrm{H}, \mathrm{s})$. These signals were attributed to the hydrogens at positions 9 , 8 and 10 of 6-endo-hydroxy-camphor (3) (Table 1). Also, the 6-endo-hydroxy-camphor (3) had coupling of $18 \mathrm{~Hz}$ between $\mathrm{H}-3_{\text {endo }}(1.99 \mathrm{ppm})$ and $\mathrm{H}-3_{\text {exo }}(\delta$ 2.35-2.48) for vicinal hydrogens in this position. At $2.15 \mathrm{ppm}$, we noted a triplet of the methynic hydrogen bound in position 4 of the 6-endo-hydroxy-camphor (3). The hydroxyl group assigned to the position $\mathrm{H}-\mathrm{G}_{\text {endo }}$ was responsible for the signal at 
$4.18 \mathrm{ppm}$. This showed a constant coupling at 8.0 and $2.0 \mathrm{~Hz}$. The complete structural determination of 6-endo-hydroxycamphor (3) was confirmed by comparison of ${ }^{1} \mathrm{H}$ NMR data described in the literature (Table 1). ${ }^{9}$ Other characteristic signals can be seen in Table 1 .

Table 1. ${ }^{1} \mathrm{H}$ NMR data of 6-endo-hydroxy-camphor (3) (200 MHz, $\mathrm{CDCl}_{3}$ ) obtained by hydroxylation of rac-camphor (1) using Botryosphaeria sp. CBMAI 1197

\begin{tabular}{|c|c|c|}
\hline$\stackrel{1}{\mathrm{OH}}$ & $\begin{array}{l}\text { Experimental data for } \\
\text { 6-endo-hydroxy- } \\
\text { camphor }(\mathbf{3})\end{array}$ & $\begin{array}{l}\text { Literature data for 6-endo- } \\
\text { hydroxy- } \\
\text { camphor }(\mathbf{3})^{9}\end{array}$ \\
\hline Position & $\delta_{\mathrm{H}}(J \text { in } \mathrm{Hz})^{\mathrm{a}} / \mathrm{ppm}$ & $\delta_{\mathrm{H}}(J \text { in } \mathrm{Hz})^{\mathrm{b}} / \mathrm{ppm}$ \\
\hline 3-endo & $1.99(\mathrm{~d}, 18.0)$ & $1.98(\mathrm{~d}, 18.5)$ \\
\hline 3-exo & $2.35-2.48(\mathrm{~m})$ & $2.43(\mathrm{ddd}, 18.5,5.0,3.0)$ \\
\hline 4 & $2.15(\mathrm{t}, 4.0)$ & $2.14(\mathrm{dd}, 5.0,4.5)$ \\
\hline 5-endo & $1.34(\mathrm{dd}, 14.0,2.0)$ & $1.33(\mathrm{dd}, 13.5,2.5)$ \\
\hline $5-e x o$ & $2.50-2.61(\mathrm{~m})$ & $\begin{array}{c}2.54 \text { (dddd, } 13.5,10.0 \\
4.5,3)\end{array}$ \\
\hline 6-exo & $4.18(\mathrm{dd}, 8.0,2.0)$ & $4.16(\mathrm{dd}, 10,2.5)$ \\
\hline 8 and 10 & $0.98(\mathrm{~s}, 6 \mathrm{H})$ & $0.96(\mathrm{~s}, 6 \mathrm{H})$ \\
\hline 9 & $0.83(\mathrm{~s}, 3 \mathrm{H})$ & $0.82(\mathrm{~s}, 3 \mathrm{H})$ \\
\hline
\end{tabular}

The fraction B chromatogram (Figure 3B) showed compound $\mathbf{5}$ as the majority presence. The carbinolic hydrogen region of the ${ }^{1} \mathrm{H}$ NMR spectrum showed a double doublet at $4.02 \mathrm{ppm}$ that was attributed to the 5-endohydrogen yielding 5-exo-hydroxycamphor (5). This doublet had coupling constants of 6.0 and $4.0 \mathrm{~Hz}$ indicating an endo-endo correlation between the hydrogens in positions $\mathrm{H}-5$ and H-6, and endo-exo between the 5-endo-hydrogen and 6-exo-hydrogen, respectively. The other signals were compared with the literature and corroborated the characterization of 5-exo-hydroxycamphor (5) (Table 2). ${ }^{9}$

The ${ }^{1} \mathrm{H}$ NMR spectrum of fraction $\mathrm{C}$ (Figure 3C and Supplementary Information) showed the presence of three groups with characteristic signal for carbinolic hydrogens. The majority signal at $4.18 \mathrm{ppm}$ concerned the 6-exo-hydrogen of 6-endo-hydroxycamphor (3). The signal at $4.02 \mathrm{ppm}$ was the 5-endo-hydrogen of 5-exo-hydroxycamphor (5), and the other signal type multiplet was at 4.58-4.66 ppm and was assigned to 5-exohydrogen of 5-endo-hydroxycamphor (6) (Figure 5). This characterization agrees with the data obtained by Miyazawa and Miyamoto ${ }^{9}$ who proposed substance $\mathbf{6}$ presents a shield in $4.64 \mathrm{ppm}$ as a dddd $(J=9.5,4.5,4.0$ and $2.0 \mathrm{~Hz})$.

Fraction D (Figure 2D and Supplementary Information) showed hydroxylation at 6-endo for compound $\mathbf{3}(4.18 \mathrm{ppm}$, $\mathrm{dd}, J=8.0$. and $2.0 \mathrm{~Hz}$ ), 5-exo for compound $5(\delta 4.02)$ and 5-endo for compound $\mathbf{6}(\delta 4.58-4.66, \mathrm{~m})$. In addition,
Table 2. ${ }^{~} \mathrm{H}$ NMR data of 5-exo-hydroxy-camphor (5) (200 MHz, $\mathrm{CDCl}_{3}$ ) obtained by hydroxylation of rac-camphor (1) using Botryosphaeria sp. CBMAI 1197

\begin{tabular}{|c|c|c|}
\hline & $\begin{array}{l}\text { Experimental data for } \\
\text { 5-exo-hydroxy- } \\
\text { camphor (5) }\end{array}$ & $\begin{array}{l}\text { Literature data for 5-exo- } \\
\text { hydroxy-camphor }(\mathbf{5})^{9}\end{array}$ \\
\hline Position & $\delta_{\mathrm{H}}(J \text { in } \mathrm{Hz})^{\mathrm{a}} / \mathrm{ppm}$ & $\delta_{\mathrm{H}}(J \text { in } \mathrm{Hz})^{\mathrm{b}} / \mathrm{ppm}$ \\
\hline 3-endo & $1.70(\mathrm{~d}, 18.0)$ & $1.70(\mathrm{~d}, 18.5)$ \\
\hline 3-exo & $2.34(\mathrm{~d}, 18.0,6.0)$ & $2.33(\mathrm{dd}, 18.5,5.0)$ \\
\hline 4 & $2.16(\mathrm{~d}, 6.0)$ & $2.16(\mathrm{dd}, 5.0,1.0)$ \\
\hline 5-endo & $4.02(\mathrm{dd}, 6.0,4.0)$ & $4.02(\mathrm{dd}, 7.5,3.5)$ \\
\hline 6-endo & $1.85(\mathrm{~m})$ & $1.85(\mathrm{dd}, 14.0,7.5)$ \\
\hline 6-exo & $1.81(\mathrm{~m})$ & $1.79(\mathrm{ddd}, 14.0,3.5,1.0)$ \\
\hline 8 & $0.85(\mathrm{~s}, 3 \mathrm{H})$ & $0.85(\mathrm{~s}, 6 \mathrm{H})$ \\
\hline 9 & $1.25(\mathrm{~s}, 3 \mathrm{H})$ & $1,25(\mathrm{~s}, 3 \mathrm{H})$ \\
\hline 10 & $0.93(\mathrm{~s}, 3 \mathrm{H})$ & $0.93(\mathrm{~s}, 3 \mathrm{H})$ \\
\hline
\end{tabular}

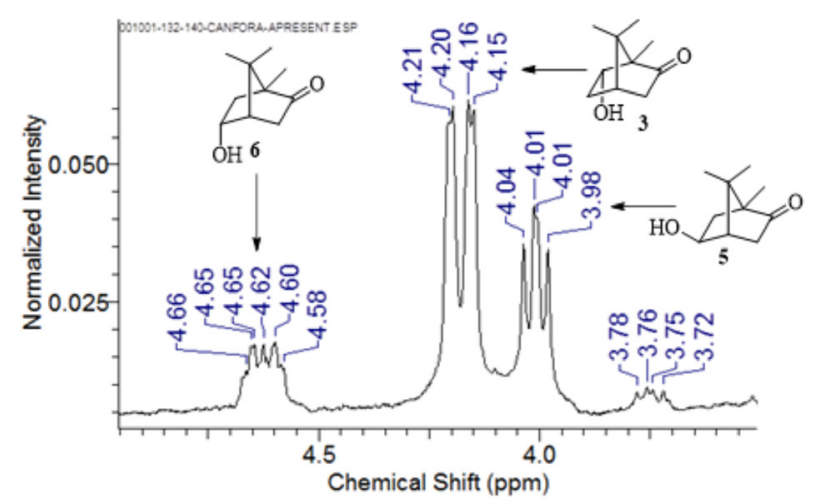

Figure 5. Specific signals obtained by ${ }^{1} \mathrm{H}$ NMR spectrum for carbinolic hydrogens of monohydroxylated derivatives $(\mathbf{3}, \mathbf{5}$ and $\mathbf{6})$ of rac-camphor (1) obtained from fraction $\mathrm{C}$.

there were two doublets at $3.50 \mathrm{ppm}(\mathrm{d}, J=12.0 \mathrm{~Hz})$ and $3.74 \mathrm{ppm}(\mathrm{d}, J=12.0 \mathrm{~Hz})$. This is usually designated as the roof effect and was allocated to two diastereotopic carbinolic hydrogens of 8-hydroxycamphor (7) (Figure 6). Miyazawa and Miyamoto 9 assigned readings on $3.52 \mathrm{ppm}$ $(\mathrm{d}, J=11.0 \mathrm{~Hz})$ and $3.74 \mathrm{ppm}(\mathrm{d}, J=11.0 \mathrm{~Hz})$ to hydrogens of C-8 of 8-hydroxycamphor (7).

Finally, compound $\mathbf{2}$ was not isolated, and there are ten sites of hydroxylation in the rac-camphor (1) (Figure 7). Compound $\mathbf{2}$ might have been a possible hydroxylated stereoisomer according to the data of spectrum mass. This was suggested at position-2 (Figure 2 and Supplementary Information).

This study showed the camphor biotransformation by a marine environment fungus. The identification of monohydroxylated products from the oxidation of camphor is important for the identification of metabolites or the use of hydroxylated derivatives of camphor in pharmaceutical formulations. 


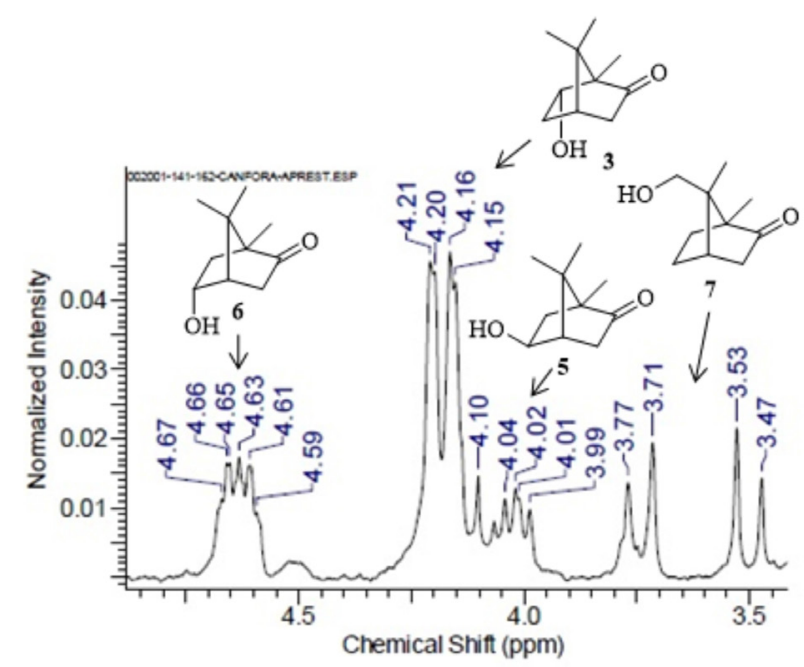

Figure 6. Specific signals obtained by ${ }^{1} \mathrm{H}$ NMR spectrum for carbinolic hydrogens of monohydroxylated derivatives $(\mathbf{3}, \mathbf{5}, \mathbf{6}$ and 7) of rac-camphor (1) obtained from fraction D.

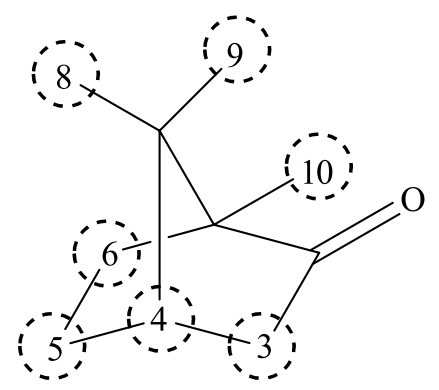

Figure 7. Possible sites of monohydroxylation of rac-camphor (1) to obtain stereoisomers. Compounds identified had the positions C-3, C-5, C-6 and C-8 hydroxylated.

\section{Conclusions}

The Brazilian marine-derived fungus Botryosphaeria sp. CBMAI 1197 is an efficient biocatalyst that promotes mono-biohydroxylation of rac-camphor (1). The main biotransformation product was 6-endo-hydroxycamphor (3) reaching $49 \%$ after 5 days of reaction followed by 5 -exohydroxycamphor (5), 5-endo-hydroxycamphor (6), 6-exohydroxycamphor (4) and 8-hydroxycamphor (7). Chemical modifications in non-activated carbon atoms such as $\mathrm{sp}^{3}$ camphor carbons usually cannot be done by conventional organic synthesis.

\section{Supplementary Information}

We would like to inform that this manuscript presents to the reader the supplementary information (NMR spectra and proposal of MS fragmentation for identified compounds), available free of charge at http://jbcs.sbq.org.br.

\section{Acknowledgments}

H. C. R. J. thanks to Coordenação de Aperfeiçoamento de Pessoal de Nível Superior (CAPES) for scholarships. The authors thank to Conselho Nacional de Desenvolvimento Científico e Tecnológico (CNPq) and Fundação de Amparo à Pesquisa do Estado de São Paulo (FAPESP) for financial support. A. L. M. P. thanks to $15^{\text {th }}$ Anniversary of the BIOprospecTA-BIOTA program.

\section{References}

1. Langenheim, J. H.; J. Chem. Ecol. 1994, 20, 1223.

2. Damjanoviae-Vratnica, B.; Dakov, T.; Sukoviae, D.; Damjanoviae, J.; J. Essent. Oil-Bear. Plants 2008, 11, 79.

3. Tucker, A. O.; Maciarello, M. J.; J. Essent. Oil Res. 1990, 2, 139.

4. Abu-Darwish, M. S.; Cabral, C.; Ferreira, I. V.; Gonçalves, M. J.; Cavaleiro, C.; Cruz, M. T.; Al-bdour, T. H.; Salgueiro, L.; Biomed. Res. Int. 2013, 538940, 1.

5. Bakkali, F.; Averbeck, S.; Averbeck, D.; Idaomar, M.; Food Chem. Toxicol. 2008, 46, 446.

6. Schwab, W.; Fuchs, C.; Huang, F.-C.; Eur. J. Lipid Sci. Technol. 2013, 115, 3.

7. Prasad, B.; Rojubally, A.; Plettner, E.; J. Chem. Ecol. 2011, 37, 657.

8. Nakahashi, H.; Miyazawa, M.; J. Oleo Sci. 2011, 60, 545.

9. Miyazawa, M.; Miyamoto, Y.; J. Mol. Catal. B: Enzym. 2004, $27,83$.

10. Martins, M. P.; Ouazzani, J.; Arcile, G.; Jeller, A. H.; Lima, J. P. F.; Seleghim, M. H. R.; Oliveira, A. L. L.; Debonsi, H. M.; Venâncio, T.; Yokoya, N. S.; Fujii, M. T.; Porto, A. L. M.; Mar. Biotechnol. 2015, 17, 211.

11. Mouad, A. M.; Martins, M. P.; Debonsi, H. M.; De Oliveira, A. L. L.; De Felicio, R.; Yokoya, N. S.; Fujii, M. T.; De Menezes, C. B. A.; Fantinatti-Garboggini, F.; Porto, A. L. M.; Helv. Chim. Acta 2011, 94, 1506.

12. Despreaux, C. W.; Rittweger, K. R.; Palleroni, N. J.; Appl. Environ. Microb. 1986, 51, 946.

13. Furusawa, M.; Hashimoto, T.; Noma, Y.; Asakawa, Y.; Chem. Pharm. Bull. 2005, 53, 1423.

14. Asakawa, Y.; Hashimoto, T.; Noma, Y.; Furusawa, M.; Nat. Prod. Commun. 2013, 8, 859.

15. Grogan, G.; Roberts, G. A.; Parsons, S.; Turner, N. J.; Flitsch, S. L.; Appl. Microbiol. Biotechnol. 2002, 59, 449.

Submitted: June 16, 2016

Published online: September 26, 2016

FAPESP has sponsored the publication of this article. 